\title{
Raman Spectra of High- $\kappa$ Dielectric Layers Investigated with Micro-Raman Spectroscopy Comparison with Silicon Dioxide
}

\author{
P. Borowicz, ${ }^{1,2}$ A. Taube, ${ }^{1,3}$ W. Rzodkiewicz, ${ }^{1}$ M. Latek, ${ }^{1}$ and S. Gierałtowska ${ }^{4}$ \\ ${ }^{1}$ Institute of Electron Technology, Al. Lotników 32/46, 02-668 Warsaw, Poland \\ ${ }^{2}$ Institute of Physical Chemistry, Polish Academy of Sciences, Kasprzaka 44/52, 01-224 Warsaw, Poland \\ ${ }^{3}$ Institute of Microelectronics and Optoelectronics, Warsaw University of Technology, Koszykowa 75, 00-662 Warsaw, Poland \\ ${ }^{4}$ Institute of Physics, Polish Academy of Sciences, Al. Lotników 32/46, 02-668 Warsaw, Poland
}

Correspondence should be addressed to P. Borowicz; psborowicz@wp.pl

Received 30 April 2013; Accepted 31 July 2013

Academic Editors: D. Acevedo, A. G. Magalhães, and A. Tonkikh

Copyright (C) 2013 P. Borowicz et al. This is an open access article distributed under the Creative Commons Attribution License, which permits unrestricted use, distribution, and reproduction in any medium, provided the original work is properly cited.

Three samples with dielectric layers from high- $\kappa$ dielectrics, hafnium oxide, gadolinium-silicon oxide, and lanthanum-lutetium oxide on silicon substrate were studied by Raman spectroscopy. The results obtained for high- $\kappa$ dielectrics were compared with spectra recorded for silicon dioxide. Raman spectra suggest the similarity of gadolinium-silicon oxide and lanthanum-lutetium oxide to the bulk nondensified silicon dioxide. The temperature treatment of hafnium oxide shows the evolution of the structure of this material. Raman spectra recorded for as-deposited hafnium oxide are similar to the results obtained for silicon dioxide layer. After thermal treatment especially at higher temperatures $\left(600^{\circ} \mathrm{C}\right.$ and above), the structure of hafnium oxide becomes similar to the bulk non-densified silicon dioxide.

\section{Introduction}

The term high- $\kappa$ means the dielectric material which has dielectric constant higher than silicon dioxide $\left(\mathrm{SiO}_{2}\right) . \mathrm{SiO}_{2}$ is the most popular dielectric material used in technology of electronic devices due to the simple method of its production: surface oxidation. This manufacturing technique can be used in the case of circuits based on silicon or silicon carbide substrate. However, the application of $\mathrm{SiO}_{2}$ has a limitation that cannot be ignored. This limitation is leakage conductance [1]. The progress in miniaturization of electronic devices like transistor in central processing units (CPUs) implies the reduction of the thickness of dielectric layer. In the case of about $2 \mathrm{~nm}$ thick $\mathrm{SiO}_{2}$ film, the significant increase of leakage current is observed due to tunneling effect [2]. The increase of leakage current has negative influence on the electronic devices. The most important effect is the large increase of the power necessary to supply the devices. A significant part of this power is dissipated due to thermal effect, heating the device. The devices have to be efficiently cooled in order not to overcome the temperature limit of the thermal destruction. To sum up: further miniaturization of electronic devices requires dielectric materials with a larger dielectric constant than that of $\mathrm{SiO}_{2}$ [3].

Electric properties of dielectric layers depend on their molecular structures. An example of such dependence is the distribution of electric properties in MOS structures caused by distribution of mechanical stress [4]. The structure is reflected in vibrational spectra. Due to high precision, Raman spectroscopy can detect small deviations of molecular structure. The other advantage of this experimental technique is its nondestructive character. Examples of application of Raman spectroscopy for investigation of structural deviations are: analysis of mechanical stress distribution [5] and monitoring structural changes like densification caused by technological processes [6].

This work compares Raman spectra measured for three made from high- $\kappa$ materials thin films deposited on silicon substrate. The first one, hafnium oxide, was already used for fabrication of CPU devices [7]. Two others, lanthanumlutetium oxide and gadolinium-silicon oxide are candidates for application in electronic devices. Raman spectra of high- $\mathcal{\kappa}$ films are compared with data obtained for silicon dioxide layer. 


\section{Experimental}

Samples. As a reference sample, $\mathrm{Si}$ wafer covered with $\mathrm{SiO}_{2}$ layer was used. Its manufacturing was already presented in the literature [8]. Hafnium oxide $\left(\mathrm{HfO}_{2}\right)$ films were prepared with atomic layer deposition (ALD) technique. As substrates, four silicon $(\mathrm{Si})$ wafers were used. The orientation of crystallographic axes was $\langle 100\rangle$. The wafers were covered with $6 \mathrm{~nm}$ thick base silicon dioxide film prior to deposition of $\mathrm{HfO}_{2}$. Three samples were subject to rapid temperature annealing (RTA) at $400^{\circ} \mathrm{C}, 600^{\circ} \mathrm{C}$ and $800^{\circ} \mathrm{C}$. The fourth sample was used without thermal treatment (hereafter called $a$ deposited). Cooperation in respect to manufacturing of $\mathrm{HfO}_{2}$ samples was covered by the Institute of Electron Technology and Institute of Physics of Polish Academy of Sciences. Samples with gadolinium-silicon oxide $(\mathrm{GdSiO})$ and lanthanumlutetium oxide $\left(\mathrm{LaLuO}_{3}\right)$ were manufactured at Gesellschaft für Angewandte Mikro- und Optoelektronik (AMO GmbH, Niemcy). In the case of $\mathrm{GdSiO}$ a two-step procedure was used. In the first step, $\mathrm{Gd}_{2} \mathrm{O}_{3}$ layer was deposited on Si substrate. In the second step, RTA was used to achieve $\mathrm{GdSiO}$ structure. RTA process was performed at $900^{\circ} \mathrm{C}$ during $60 \mathrm{~s}$.

2.1. Apparatus. The selection of excitation wavelength is of key importance for the Raman study of dielectric layers. In the case of visible excitation, the signal generated in thin dielectric layer can be even masked by multiphonon Raman scattering generated in Si substrate [9]. Due to this large background, Raman scattering is often treated as useless in the study of thin dielectric layers [10]. Deep-ultraviolet excitation significantly reduces the penetration depth of excitation light into the silicon substrate in comparison with standard visible excitation. The reduction of this penetration depth decreases the background intensity to negligible values. As a result, the Raman scattering from dielectric layer appears in the spectrum. Raman spectrometer used in this work had the same configuration as described in the literature [8]. For ellipsometry characterization, spectroscopic ellipsometer VASE (J. A. Woollam, USA) was used.

2.2. Data Analysis. Mathematical pretreatment of the data included off-set and cosmic ray removal, baseline correction and intensity normalization. As a normalization condition, the intensity of one-phonon silicon line " $520 \mathrm{~cm}^{-1}$ " which is equal to 1 was chosen. The pretreatment was done with Grams 8 (Thermo Scientific, USA) program. The spectra measured for high- $\kappa$ materials were compared with data obtained for $\mathrm{SiO}_{2}$ layer.

\section{Results}

3.1. Spectroscopic Ellipsometry. The following samples: $\mathrm{Si} / \mathrm{SiO}_{2}$, $\mathrm{Si} / \mathrm{SiO}_{2} / \mathrm{HfO}_{2}$ (as-deposited), $\mathrm{Si} / \mathrm{GdSiO}$ and $\mathrm{Si} / \mathrm{LaLuO}_{3}$ were characterized by means of spectroscopic ellipsometry prior to Raman investigation. Other samples containing $\mathrm{HfO}_{2}$ layer were too small for these measurements. The main features: refractive index for $300 \mathrm{~nm}$ and thicknesses of the samples, are collected in Table 1. The values of refractive index measured for thin silicon dioxide film are similar to the data of
TABLE 1: Refractive indices obtained for excitation wavelength equal to $300 \mathrm{~nm}$ and film thicknesses measured by means of spectroscopic ellipsometry for silicon dioxide, hafnium oxide, gadolinium-silicon oxide, and lanthanum-lutetium oxide.

\begin{tabular}{lcc}
\hline Dielectric layer & $n(\lambda=300 \mathrm{~nm})$ & $d[\mathrm{~nm}]$ \\
\hline $\mathrm{SiO}_{2}$ & $1.495 \pm 0.005$ & $64 \pm 2$ \\
$\mathrm{HfO}_{2}$ (“as-deposited”) & $2.109 \pm 0.001$ & $46 \pm 2$ \\
$\mathrm{GdSiO}$ & $1.954 \pm 0.004$ & $47.5 \pm 0.5$ \\
$\mathrm{LaLuO}_{3}$ & $2.077 \pm 0.001$ & $8.0 \pm 0.3$ \\
\hline
\end{tabular}

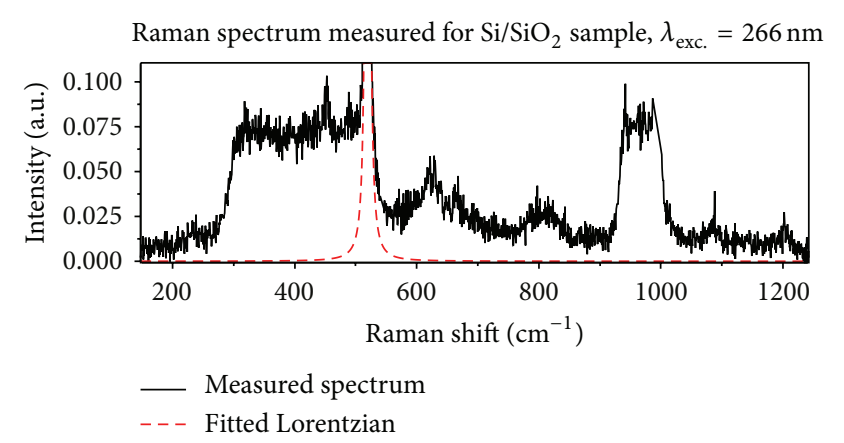

FIGURE 1: Raman spectrum measured for $\mathrm{Si} / \mathrm{SiO}_{2}$ sample, excitation wavelength $266 \mathrm{~nm}$. Black solid line represents measured data; dashed red line represents fitted Lorentzian profile modeling onephonon Si line.

bulk material reported in the literature [11]. All high- $\kappa$ materials have significantly larger optical density. The last column of Table 1 presents the thicknesses of the samples.

3.2. Raman Study. Figure 1 presents the data collected for $\mathrm{Si} / \mathrm{SiO}_{2}$ sample. Black solid line marks measured spectrum and red dashed line designates fitted Lorentzian profile modeling one-phonon silicon line. The following bands can be recognized in the spectrum (except Si line “ $520 \mathrm{~cm}^{-1}$ ”):

(i) weak band with maximum at about $230 \mathrm{~cm}^{-1}$;

(ii) relatively strong band spread from $300 \mathrm{~cm}^{-1}$ to onephonon Si line $\left(\sim 550 \mathrm{~cm}^{-1}\right)$;

(iii) band with two maxima at about $630 \mathrm{~cm}^{-1}$ and $670 \mathrm{~cm}^{-1}$;

(iv) broad band with maximum at about $810 \mathrm{~cm}^{-1}$;

(v) strong band spread from $930 \mathrm{~cm}^{-1}$ to $1030 \mathrm{~cm}^{-1}$;

(vi) two weak bands with maxima at about $1090 \mathrm{~cm}^{-1}$ and $1200 \mathrm{~cm}^{-1}$.

Raman spectra measured for silicon wafers covered with $\mathrm{HfO}_{2}$ are presented in Figure 2. Raman spectra recorded for $\mathrm{HfO}_{2}$ are similar to the data measured for $\mathrm{SiO}_{2}$ layer. The two most important common features observed for both dielectric materials can be recognized without detailed analysis:

(i) the absence of the so-called boson band;

(ii) the presence of the band between $930 \mathrm{~cm}^{-1}$ and $1030 \mathrm{~cm}^{-1}$ assigned in the literature to multi-phonon scattering generated in Si substrate [9]. 


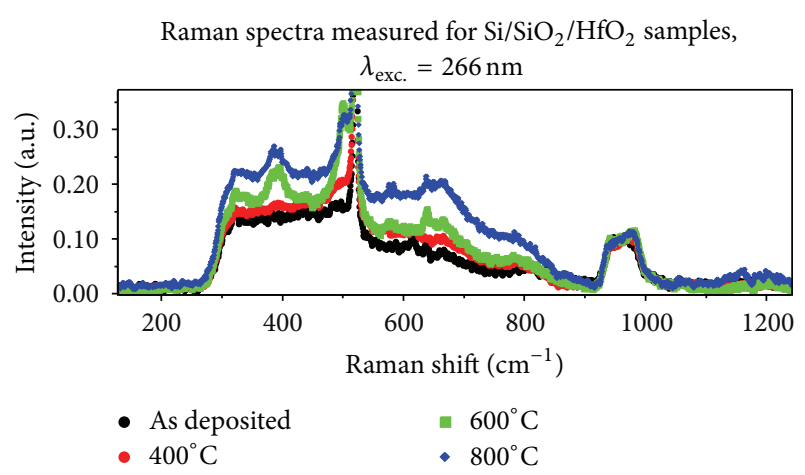

Figure 2: Raman spectra measured for $\mathrm{Si} / \mathrm{SiO}_{2} / \mathrm{HfO}_{2}$ sample, excitation wavelength $266 \mathrm{~nm}$. Black solid line represents as-deposited sample, red points represents sample annealed at $400^{\circ} \mathrm{C}$, green points represents sample annealed at $600^{\circ} \mathrm{C}$, blue points represents sample annealed at $800^{\circ} \mathrm{C}$.

The intensity of the Raman scattering observed for $\mathrm{HfO}_{2}$ layer is $2 \div 3$ times larger than the intensity recorded for $\mathrm{SiO}_{2}$ film. This comparison is done for normalized spectra. Both samples, $\mathrm{Si} / \mathrm{SiO}_{2}$ and $\mathrm{Si} / \mathrm{SiO}_{2} / \mathrm{HfO}_{2}$, have two internal standards: line " $520 \mathrm{~cm}^{-1}$ " and the multi-phonon band placed between $930 \mathrm{~cm}^{-1}$ and $1030 \mathrm{~cm}^{-1}$. Normalization of the spectra for both standards gives similar, relation between intensities of the bands assigned to vibrations in dielectric materials.

Figures 3 and 4 present Raman spectra measured for $\mathrm{LaLuO}_{3}$ and $\mathrm{GdSiO}$, respectively. In both cases excitation with second harmonic of $\mathrm{Ar}^{+}$line $488 \mathrm{~nm}(\lambda=244 \mathrm{~nm})$ was used. Both spectra are similar. The intensities of the Raman scattering recorded for $\mathrm{LaLuO}_{3}$ and $\mathrm{GdSiO}$ are about twice larger in comparison with the signal coming from $\mathrm{SiO}_{2}$ film. Since the spectra observed for $\mathrm{LaLuO}_{3}$ and $\mathrm{GdSiO}$ are similar their common features will be discussed together (see Section 4).

\section{Discussion}

Let us start from short analysis of Raman spectrum recorded for reference sample- $\mathrm{Si} / \mathrm{SiO}_{2}$ (Figure 1). The band placed between $930 \mathrm{~cm}^{-1}$ and $1030 \mathrm{~cm}^{-1}$ is assigned to multi-phonon scattering generated in $\mathrm{Si}$ substrate [9]. The other bands listed in Section 3 can be assigned to vibrations in $\mathrm{SiO}_{2}$. The $\mathrm{SiO}_{2}$ layer has a noncrytalline structure [12]. It can contain small area of quasi-crystalline form [12] like cristobalite, coesite, or crystalline quartz [13]. The area with amorphous densified structure $[14,15]$ can also appear in the $\mathrm{SiO}_{2}$ layer [12]. Taking into account data available in the literature the assignment of the observed bands to the oscillation in silicon dioxide can be done. However, one should take into account that the data reported in the literature was measured for bulk material and excitation in visible spectral range. The band with maximum at $230 \mathrm{~cm}^{-1}$ can be correlated with scissoring in $\left[\mathrm{SiO}_{4 / 2}\right]$ tetrahedron [16] or with strong line of cristobalite which has the maximum for the same value of Raman shift [13]. The main band placed between $300 \mathrm{~cm}^{-1}$ and $550 \mathrm{~cm}^{-1}$ can be
Raman spectrum measured for $\mathrm{Si} / \mathrm{LaLuO}_{3}$ sample, $\lambda_{\text {exc. }}=244 \mathrm{~nm}$

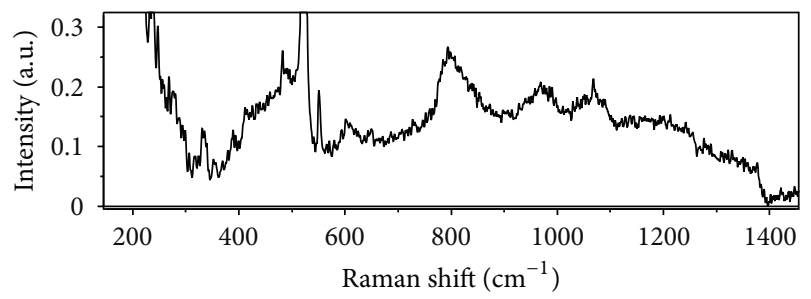

FIgure 3: Raman spectrum measured for $\mathrm{Si} / \mathrm{LaLuO}_{3}$ sample, excitation wavelength $244 \mathrm{~nm}$.

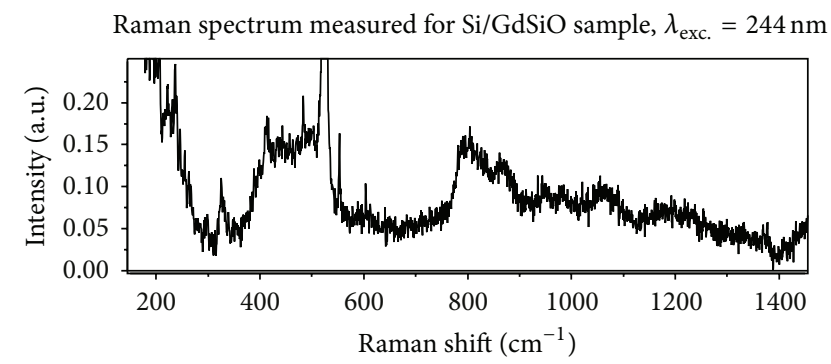

FIgURE 4: Raman spectrum measured for $\mathrm{Si} / \mathrm{GdSiO}$ sample, excitation wavelength $244 \mathrm{~nm}$.

a combination of several bands. The following $\mathrm{SiO}_{2}$ vibration can contribute to this band:

(i) scissoring in extended tetrahedron $\left[\mathrm{SiO}_{4 / 2}\right]-\left[\mathrm{Si}_{4 / 4}\right]$ labeled by $\mathrm{D}_{3}[16]$;

(ii) bending in rings with a number of elements equal or larger than 5 (5+ rings) labeled by $\mathrm{D}_{4}[16]$;

(iii) bending in Si-O-Si bridges labeled by R [16];

(iv) vibration associated with four-member rings, socalled defect band, labeled by $\mathrm{D}_{1}[16]$.

Strong lines from crystalline forms of $\mathrm{SiO}_{2}$ are also placed in the range of Raman shift between $300 \mathrm{~cm}^{-1}$ and $550 \mathrm{~cm}^{-1}$ [13]. However, the contribution of the crystalline structures is so small that their intensities do not exceed the signal-tonoise ratio [12]. $\mathrm{D}_{1}$ band has the maximum at about $490 \mathrm{~cm}^{-1}$ in non-densified structure and at about $520 \mathrm{~cm}^{-1}$ in densified structure $[6,12,14]$. This band is placed so close to the onephonon Si line that it is impossible to recognize it without mathematical analysis of the spectrum. The densification of $\mathrm{SiO}_{2}$ layer is reflected in the shape and position of the next two bands having maxima at about $620 \mathrm{~cm}^{-1}$ and $800 \mathrm{~cm}^{-1}$ $[6,14,15]$. The band with the maximum at about $670 \mathrm{~cm}^{-1} \mathrm{can}$ be correlated with strong line reported for coesite and having the maximum at $661 \mathrm{~cm}^{-1}$ [13]. The bands placed around $1090 \mathrm{~cm}^{-1}$ and $1200 \mathrm{~cm}^{-1}$ are assigned to $\mathrm{Si}-\mathrm{O}$ stretching vibration [14]. The last important feature of Raman spectrum recorded for $\mathrm{SiO}_{2}$ thin film is the absence of boson band observed for visible excitation in the case of bulk material [14]. It should be emphasized that boson band was not observed for bulk $\mathrm{SiO}_{2}$ in the case of deep ultraviolet excitation $[8]$. 
The bands observed for $\mathrm{HfO}_{2}$ and placed above $1000 \mathrm{~cm}^{-1}$ are much weaker than similar bands in $\mathrm{SiO}_{2}$ spectrum. The most important difference between Raman scattering observed for silicon dioxide and hafnium oxide is the shape of the spectrum in the range between $300 \mathrm{~cm}^{-1}$ and $930 \mathrm{~cm}^{-1}$. In the case of $\mathrm{SiO}_{2}$ three separate bands can be recognized in the spectrum: the main band placed between $300 \mathrm{~cm}^{-1}$ and $550 \mathrm{~cm}^{-1}, \mathrm{D}_{2}$ band placed around $620 \mathrm{~cm}^{-1}$ and a band " $800 \mathrm{~cm}^{-1}$ ". In the spectrum observed for $\mathrm{HfO}_{2}$ film the bands are merged in such a way that the main band placed between $300 \mathrm{~cm}^{-1}$ and $550 \mathrm{~cm}^{-1}$ has a tail extended to $930 \mathrm{~cm}^{-1}$. In the case of the spectrum observed for the sample, as-deposited weak band placed around $800 \mathrm{~cm}^{-1}$ can be recognized on this tail. The range $600 \mathrm{~cm}^{-1}-700 \mathrm{~cm}^{-1}$ contains no unambiguous band. The main band placed between $300 \mathrm{~cm}^{-1}$ and $550 \mathrm{~cm}^{-1}$ is similar for spectra recorded for $\mathrm{SiO}_{2}$ and $\mathrm{HfO}_{2}$ as-deposited films.

Let us compare Raman spectra of $\mathrm{HfO}_{2}$ recorded film after thermal treatment. In the case of the sample annealed at $400^{\circ} \mathrm{C}$, only a small increase of the main band intensity is observed. No changes in the shape of the spectrum appear. Annealing at higher temperature $\left(600^{\circ} \mathrm{C}\right.$ and $\left.800^{\circ} \mathrm{C}\right)$ leads to a significant increase of the Raman scattering intensity combined with changes of the shape of the spectrum. The following bands (maxima) appear in the spectra of $\mathrm{Si} / \mathrm{SiO}_{2} / \mathrm{HfO}_{2}$ samples annealed at $600^{\circ} \mathrm{C}$ and $800^{\circ} \mathrm{C}: 320 \mathrm{~cm}^{-1}, 380 \mathrm{~cm}^{-1}$, $600 \mathrm{~cm}^{-1}, 670 \mathrm{~cm}^{-1}$. An additional relatively narrow band appears near the Si one-phonon line. The band is merged with " $520 \mathrm{~cm}^{-1}$ " line, and its maximum is placed at about $490 \mathrm{~cm}^{-1}$. The weak band placed around $800 \mathrm{~cm}^{-1}$ becomes stronger, and its maximum shifts towards smaller values of Raman shift by about $10 \mathrm{~cm}^{-1}$. The following analogies can be drawn between bands observed for annealed $\mathrm{HfO}_{2}$ film and the data reported for bulk $\mathrm{SiO}_{2}$ in the literature:

(i) band with the maximum at $320 \mathrm{~cm}^{-1}$ corresponds to $\mathrm{D}_{3}$ band assigned to scissoring in extended tetrahedron $\left[\mathrm{SiO}_{4 / 2}\right]-\left[\mathrm{Si}_{4 / 4}\right]$;

(ii) band with the maximum at $380 \mathrm{~cm}^{-1}$ corresponds to $\mathrm{D}_{4}$ band assigned to bending in 5+ rings in $\mathrm{SiO}_{2}$;

(iii) band with the maximum at $430 \mathrm{~cm}^{-1}$ corresponds to $\mathrm{R}$ band assigned to bending in $\mathrm{Si}-\mathrm{O}-\mathrm{Si}$ bridges;

(iv) band with the maximum at $490 \mathrm{~cm}^{-1}$ corresponds to $\mathrm{D}_{1}$ defect band assigned to vibrations in 4-members rings in $\mathrm{SiO}_{2}$ structure;

(v) band with the maximum at $600 \mathrm{~cm}^{-1}$ corresponds to $\mathrm{D}_{2}$ defect band assigned to vibrations in 3-member rings in $\mathrm{SiO}_{2}$ structure;

(vi) band with the maximum at $800 \mathrm{~cm}^{-1}$ corresponds to complex so-called " $800 \mathrm{~cm}^{-1}$ " band in $\mathrm{SiO}_{2}$ structure [14].

The positions and shapes of Raman band equivalents of $D_{1}$, $\mathrm{D}_{2}$ and " $800 \mathrm{~cm}^{-1}$ " recorded for the samples $\mathrm{Si} / \mathrm{SiO}_{2} / \mathrm{HfO}_{2}$ are similar to the data reported for non-densified bulk $\mathrm{SiO}_{2}$. In the case of silicon oxide layer, bands $\mathrm{D}_{2}$ and " $800 \mathrm{~cm}^{-1}$ " suggest densified character of the film.
The first feature that appears in spectra recorded for $\mathrm{LaLuO}_{3}$ and $\mathrm{GdSiO}$ is the significant signal below $300 \mathrm{~cm}^{-1}$. It corresponds to boson band reported for excited with visible light Raman scattering from bulk $\mathrm{SiO}_{2}$ [14]. The absence of the relatively strong band in the range of Raman shift between $930 \mathrm{~cm}^{-1}$ and $1030 \mathrm{~cm}^{-1}$ assigned to second order scattering in $\mathrm{Si}$ substrate is also observed for both dielectric layers $\left(\mathrm{LaLuO}_{3}\right.$ and $\left.\mathrm{GdSiO}\right)$. Small differences between Raman spectra of $\mathrm{LaLuO}_{3}$ and $\mathrm{GdSiO}$ in this range of Raman shift will be discussed later. Spectra recorded for $\mathrm{LaLuO}_{3}$ and $\mathrm{GdSiO}$ contain not only broad bands, but also narrow lines. full width at half maximum (FWHM) of these lines is the order of $1 \mathrm{~cm}^{-1}$. It suggests vibrations of crystalline structures as origin of these lines. Amorphous structures generate bands with FWHM at the order of $10 \mathrm{~cm}^{-1}$. The first line appearing in the scattering observed for both dielectrics has the maximum at about $330 \mathrm{~cm}^{-1}$. This line has the best correlation with two strong lines reported for tridymite. These lines are centered around $320 \mathrm{~cm}^{-1}$ and $355 \mathrm{~cm}^{-1}$ [13]. Broad band merged with one-phonon Si line starts between $380 \mathrm{~cm}^{-1}$ and $400 \mathrm{~cm}^{-1}$ and is significantly narrower in comparison with the main band observed for $\mathrm{SiO}_{2}$ layer. One narrow line appears in the range of Raman shift between $380 \mathrm{~cm}^{-1}$ and $540 \mathrm{~cm}^{-1}$ against the background of the main broad band. The maximum of this line equals $390 \mathrm{~cm}^{-1}$ for $\mathrm{LaLuO}_{3}$ and $420 \mathrm{~cm}^{-1}$ in the case of $\mathrm{GdSiO}$. The line appearing within broad band has the best correlation with two strong lines of tridymite. The reported maxima positions of tridymite lines are equal to $403 \mathrm{~cm}^{-1}$ and $422 \mathrm{~cm}^{-1}$ [13]. The main broad band has different shapes for $\mathrm{LaLuO}_{3}$ and $\mathrm{GdSiO}$. In the case of $\mathrm{LaLuO}_{3}$ (Figure 3) the fast increase of the band intensity is observed for Raman shift in the range $380 \mathrm{~cm}^{-1}-420 \mathrm{~cm}^{-1}$. It is followed by lower increase in the range $420 \mathrm{~cm}^{-1}$ $500 \mathrm{~cm}^{-1}$. In the range of Raman shift between $500 \mathrm{~cm}^{-1}$ and $540 \mathrm{~cm}^{-1}$ one-phonon $\mathrm{Si}$ line dominates in Raman spectrum. One narrow line with the maximum at $480 \mathrm{~cm}^{-1}$ and slightly broader band with the maximum at $490 \mathrm{~cm}^{-1}$ appear in $\mathrm{LaLuO}_{3}$ spectrum. Narrow line can be compared with following lines reported for crystalline structures of $\mathrm{SiO}_{2}$ : tridymite $\left(457 \mathrm{~cm}^{-1}\right)$, crystalline quartz $\left(465 \mathrm{~cm}^{-1}\right)$, or moganite $\left(501 \mathrm{~cm}^{-1}\right)$ [13]. Broader band has the same position as $\mathrm{D}_{1}$ reported for non-densified form of bulk $\mathrm{SiO}_{2}$ [16]. In the case of $\mathrm{GdSiO}$ the fast increase of the main band intensity is observed in the range of Raman shift $380 \mathrm{~cm}^{-1}-400 \mathrm{~cm}^{-1}$. Except previously discussed narrow line with the maximum at $420 \mathrm{~cm}^{-1}$ two band with maxima at $430 \mathrm{~cm}^{-1}$ and $490 \mathrm{~cm}^{-1}$ can be recognized in the spectrum. The band with the maximum at $430 \mathrm{~cm}^{-1}$ has the best correlation with band $\mathrm{R}$ reported for $\mathrm{SiO}_{2}$ spectrum. Band with the maximum at $490 \mathrm{~cm}^{-1}$ has the best correlation with $\mathrm{D}_{1}$ band reported for non-densified bulk silicon oxide. Appearing in $\mathrm{LaLuO}_{3}$ spectrum line with the maximum at $480 \mathrm{~cm}^{-1}$ has very small FWHM. Narrow line with the maximum at about $550 \mathrm{~cm}^{-1}$ appears in Raman spectra of both oxides: $\mathrm{LaLuO}_{3}$ and $\mathrm{GdSiO}$. The FWHM of the line observed for $\mathrm{LaLuO}_{3}$ is significantly smaller than the FWHM of the same line in $\mathrm{GdSiO}$ spectrum. The line $550 \mathrm{~cm}^{-1}$ has the best correlation with coesite line 
centered around $522 \mathrm{~cm}^{-1}$ [13]. The next two bands appearing in Raman spectra of lanthanum-lutetium oxide and gadolinium-silicon oxide have the maxima at $600 \mathrm{~cm}^{-1}$ and $640 \mathrm{~cm}^{-1}$. The bands can be correlated with $\mathrm{D}_{2}$ band reported for silicon oxide. The maximum $600 \mathrm{~cm}^{-1}$ corresponds to non-densified structure, and $640 \mathrm{~cm}^{-1}$ corresponds to densified one. The next band present in Raman spectra recorded for lanthanum-lutetium and gadolinium-silicon oxides has the maximum at about $800 \mathrm{~cm}^{-1}$. The position of the maximum and asymmetric shape of the band with steep gradient on the blue side of maximum (for smaller values of Raman shift) look like the band " $800 \mathrm{~cm}^{-1}$ " observed for nondensified bulk $\mathrm{SiO}_{2}$. The intensity of the band refering to the intensity of one-phonon $\mathrm{Si}$ line in the case of $\mathrm{LaLuO}_{3}$ and $\mathrm{GdSiO}$ is about twice larger than for silicon dioxide layer. Also the intensity ratio of the following bands " $800 \mathrm{~cm}^{-1 \text { " and }}$

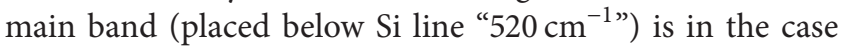
of $\mathrm{LaLuO}_{3}$ and $\mathrm{GdSiO}$ few times larger than for $\mathrm{SiO}_{2}$. In the range of Raman shift between $930 \mathrm{~cm}^{-1}$ and $1030 \mathrm{~cm}^{-1}$ the following features can be recognized:

(i) single asymmetric band with the maximum at $970 \mathrm{~cm}^{-1}$ for $\mathrm{LaLuO}_{3}$;

(ii) two band with maxima at $950 \mathrm{~cm}^{-1}$ and $980 \mathrm{~cm}^{-1}$ for GdSiO.

Raman spectra recorded for both oxide layers, $\mathrm{LaLuO}_{3}$ and $\mathrm{GdSiO}$, show broad, oval background which ranges from $650 \mathrm{~cm}^{-1}$ to $1400 \mathrm{~cm}^{-1}$. Bands described previously appear on this background. The Raman signals observed for $\mathrm{LaLuO}_{3}$ and $\mathrm{GdSiO}$ do not have typical shape of the band observed for $\mathrm{SiO}_{2}$ layer and are assigned to multi-phonon scattering from $\mathrm{Si}$ substrate [9]. It is possible that the band assigned to multi-phonon scattering is modified and partially masked by the broad background. The last two bands which can be recognized in spectra measured for lanthanum-lutetium and gadolinium-silicon oxide films have the maxima at about $1070 \mathrm{~cm}^{-1}$ and $1200 \mathrm{~cm}^{-1}$. The band with the maximum at $1070 \mathrm{~cm}^{-1}$ has a symmetric shape. The band with the maximum at $1200 \mathrm{~cm}^{-1}$ seems to be asymmetric. The tail of this band ranges up to $1400 \mathrm{~cm}^{-1}$. The bands with maxima at $1070 \mathrm{~cm}^{-1}$ and $1200 \mathrm{~cm}^{-1}$ can be correlated with bands reported for silicon oxide and assigned to the longitudinal optical (LO) and transverse optical (TO) pair of Si-O stretching vibrations $[14,17,18]$. Maxima of these bands reported in the literature are equal to about $1075 \mathrm{~cm}^{-1}$ and $1200 \mathrm{~cm}^{-1}$, respectively.

\section{Conclusions}

In earlier work, the usefulness of deep-ultraviolet Raman spectroscopy in investigation of dielectric layers in silicon based circuits was presented [8]. In this work, application of this excitation to high- $\kappa$ materials was discussed. Raman spectra of three high- $\kappa$ materials, in particular, hafnium oxide, lanthanum-lutetium oxide and gadolinium-silicon oxide were compared with silicon dioxide. All investigated materials can be divided into two groups. The first one consists of silicon oxide and hafnium oxide, and the other one consists lanthanum-lutetium oxide and gadolinium-silicon oxide. Inside each group, observed Raman spectra are similar. In the case of first group, this similarity concerns spectra of $\mathrm{SiO}_{2}$ and $\mathrm{HfO}_{2}$ as-deposited. The bands observed for high- $\kappa$ materials can be correlated with bands recorded for silicon oxide. Analysis of spectra obtained for $\mathrm{HfO}_{2}$ annealed at the temperature $600^{\circ} \mathrm{C}$ or higher as well as for $\mathrm{LaLuO}_{3}$ and $\mathrm{GdSiO}$ suggests similarity of these materials with non-densified structure bulk $\mathrm{SiO}_{2}$. The structure of following layers: $\mathrm{SiO}_{2}, \mathrm{HfO}_{2}$ as-deposited and $\mathrm{HfO}_{2}$ annealed at $400{ }^{\circ} \mathrm{C}$ seems to be similar to densified bulk silicon dioxide.

The intensity of Raman scattering generated by hafnium oxide, lanthanum-lutetium oxide, and gadolinium-silicon oxide layers is 2-3 times higher than scattering from silicon oxide layer. The comparison is done for intensities related to the intensity of one-phonon line from silicon substrate.

The last point to sum up is the behavior of Raman spectra in the range $930 \mathrm{~cm}^{-1}-1030 \mathrm{~cm}^{-1}$. In the case of $\mathrm{HfO}_{2}$ and $\mathrm{SiO}_{2}$ layers, the band appearing in this range is similar to the data reported for multi-phonon scattering from silicon. For $\mathrm{LaLuO}_{3}$ and $\mathrm{GdSiO}$, bands in this range of Raman shift are mixed with broad and oval background ranging from $650 \mathrm{~cm}^{-1}$ to $1400 \mathrm{~cm}^{-1}$. This background can modify the shape of observed bands.

\section{Acknowledgments}

This work is financed by European Union under European Regional Development Fund as Grant Innovative Economy (POIG.01.03.01-00-159/08, "InTechFun"). A. Taube received support from European Union under European Social Fund, project "Development Program of Warsaw University of Technology" realized by Center of Advanced Studies. S. Gierałtowska received support from European Union under European Regional Development Fund as Grant Innovative Economy (POIG.01.01.02-00-008/08, "NanoBiom").

\section{References}

[1] K. Roy, S. Mukhopadhyay, and H. Mahmoodi-Meimand, "Leakage current mechanisms and leakage reduction techniques in deep-submicrometer CMOS circuits," Proceedings of the IEEE, vol. 91, no. 2, pp. 305-327, 2003.

[2] J.-S. Lee, "Improving performance and reliability of MOS devices using deuterium implantation," in Cutting Edge Nanotechnology, D. Vasileska, Ed., pp. 15-32, InTech, University Campus STeP Ri, Rijeka, Croatia, 2010, http://www.intechopen.com/ books/cutting-edge-nanotechnology/improving-performanceand-reliability-of-mos-devices-using-deuterium-implantation.

[3] S. Hall, O. Buiu, I. Z. Mitrovic, Y. Lu, and W. M. Davey, "Review and perspective of high-k dielectrics on silicon," Journal of Telecommunication and Information Technology, vol. 2, pp. 33-43, 2007.

[4] H. M. Przewłocki, A. Kudła, K. Piskorski, and D. Brzezińska, "Distributions of barrier heights, difference of effective contact potential, and local values of flat-band voltage in $\mathrm{Al}-\mathrm{SiO}_{2}-\mathrm{Si}$ and poly-Si-SiO 2 -Si structures," Thin Solid Films, vol. 516, no. 12, pp. 4184-4189, 2008. 
[5] I. De Wolf, J. Vanhellemont, A. Romano-Rodríguez, H. Norström, and H. E. Maes, "Micro-Raman study of stress distribution in local isolation structures and correlation with transmission electron microscopy," Journal of Applied Physics, vol. 71, no. 2, pp. 898-906, 1992.

[6] G. E. Walrafen and P. N. Krishnan, "Raman spectrum of pressure compacted fused silica," The Journal of Chemical Physics, vol. 74, no. 9, pp. 5328-5330, 1981.

[7] L. Milgrom, Hafnium Oxide Helps Make Chips Smaller and Faster, Chemistry World, RSC Advancing the Chemical Science, February 2007, http://www.rsc.org/chemistryworld/News/ 2007/February/05020702.asp.

[8] Borowicz, M. Latek, W. Rzodkiewicz, A. Laszcz, A. Czerwinski, and J. Ratajczak, "Deep ultraviolet Raman investigation of silicon oxide: thin film on silicon substrate versus bulk material," Advances in Natural Sciences: Nanoscience and Nanotechnology, vol. 3, Article ID 045003, 2012.

[9] P. A. Temple and C. E. Hathaway, "Multiphonon Raman spectrum of silicon," Physical Review B, vol. 7, no. 8, pp. 3685-3697, 1973.

[10] A. Chabli, "Optical characterization of layers for silicon microelectronics," Microelectronic Engineering, vol. 40, no. 3-4, pp. 263-274, 1998.

[11] J. Jasny, B. Nickel, and P. Borowicz, "Wavelength- and temperature-dependent measurement of refractive indices," Journal of the Optical Society of America B, vol. 21, no. 4, pp. 729-738, 2004.

[12] A. G. Revesz and H. L. Hughes, "The structural aspects of non-crystalline $\mathrm{SiO}_{2}$ films on silicon: a review," Journal of NonCrystalline Solids, vol. 328, no. 1-3, pp. 48-63, 2003.

[13] K. J. Kingma and R. J. Hemley, "Raman spectroscopic study of microcrystalline silica," American Mineralogist, vol. 79, no. 3-4, pp. 269-273, 1994.

[14] G. E. Walrafen, Y. C. Chu, and M. S. Hokmabadi, "Raman spectroscopic investigation of irreversibly compacted vitreous silica," The Journal of Chemical Physics, vol. 92, no. 12, pp. 69877002, 1990.

[15] B. Champagnon, C. Martinet, M. Boudeulle et al., "High pressure elastic and plastic deformations of silica: in situ diamond anvil cell Raman experiments," Journal of Non-Crystalline Solids, vol. 354, no. 2-9, pp. 569-573, 2008.

[16] M. Chligui, G. Guimbretière, A. Canizarès, G. Matzen, Y. Vaills, and P. Simon, "Key-points in the improvement on structure knowledge," version 24, September 2010, http://hal.archivesouvertes.fr/docs/00/52/08/23/PDF/chliguiSiO2.pdf.

[17] P. G. Pai S, S. Chao, and Y. Takagi, "Infrared spectroscopic study of $\mathrm{SiO}_{x}$ films produced by plasma enhancedchemical vapor deposition," Journal of Vacuum Science Technology A, vol. 4, pp. 689-694, 1986.

[18] M. K. Gunde, "Vibrational modes in amorphous silicon dioxide," Physica B, vol. 292, no. 3-4, pp. 286-295, 2000. 

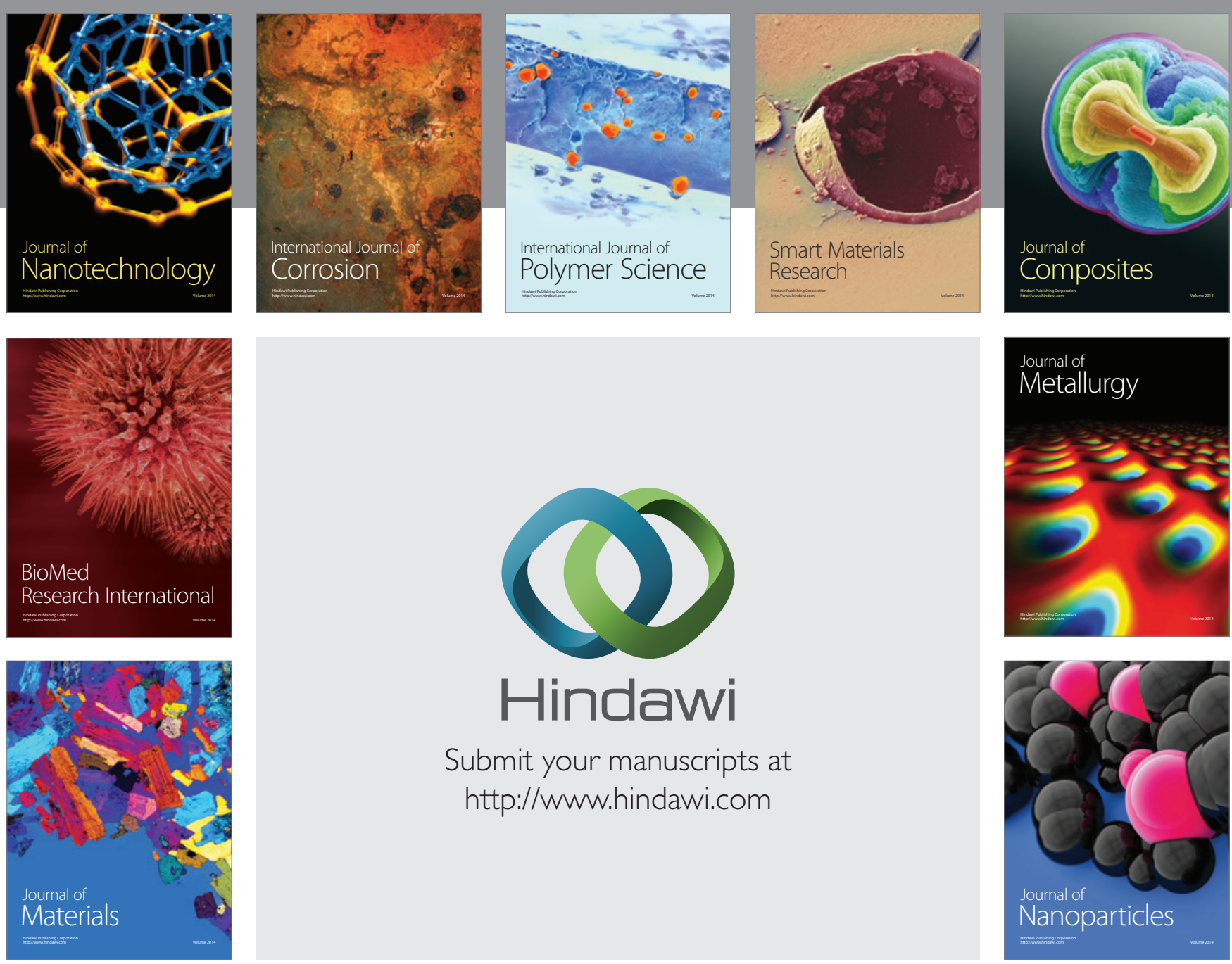

Submit your manuscripts at http://www.hindawi.com
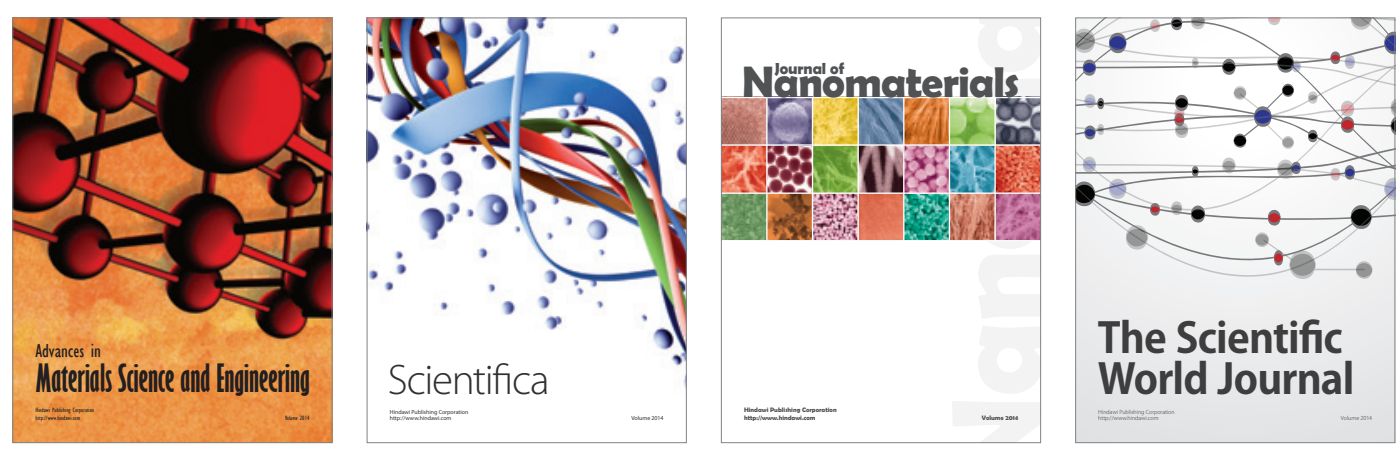

\section{The Scientific World Journal}
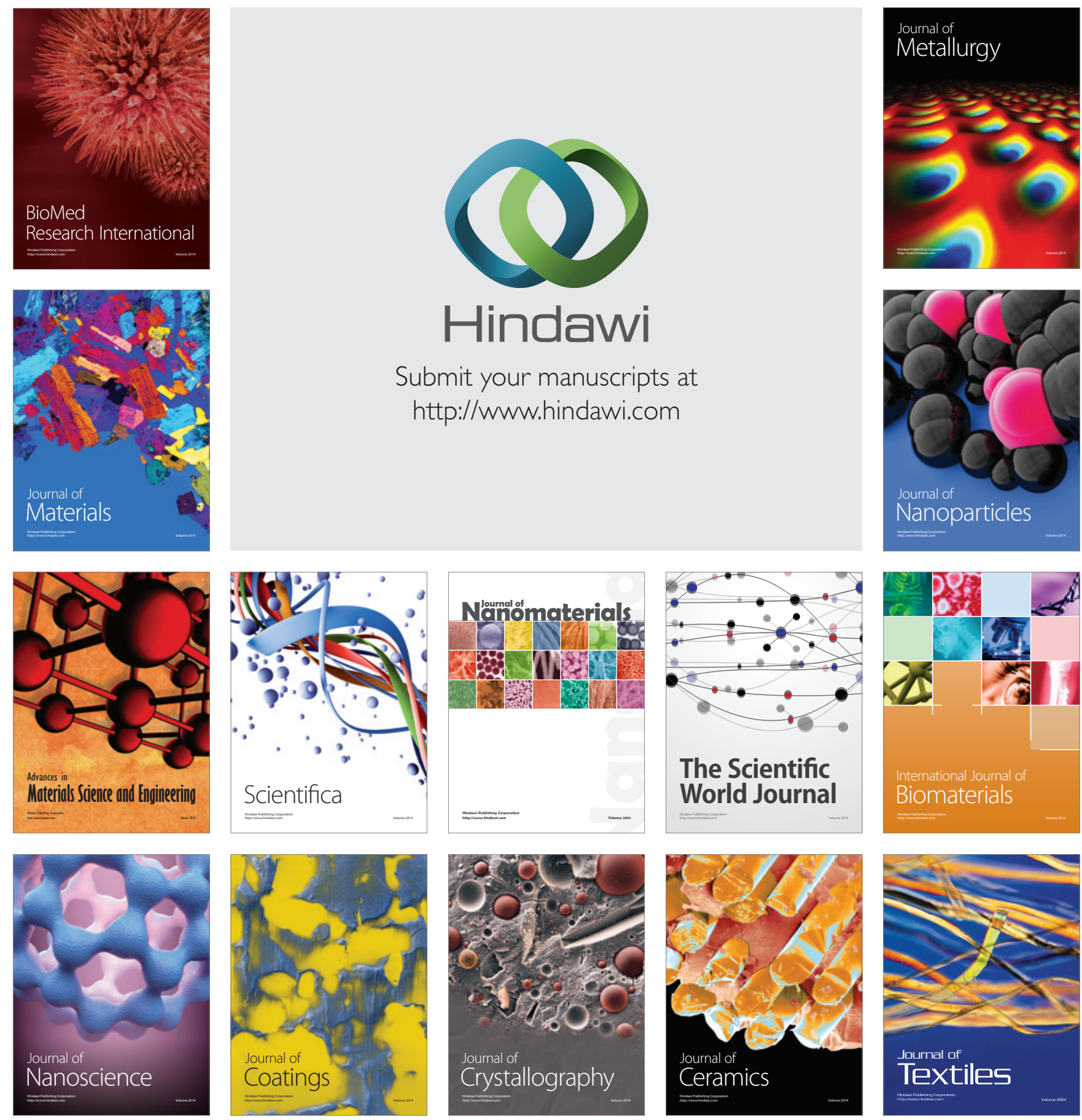